\title{
LAS LAGUNAS PUNITIVAS DEL DELITO DE FINANCIACIÓN ILEGAL DE PARTIDOS POLÍTICOS: ESPECIAL REFERENCIA A LAS CONDONACIONES DE DEUDA POR LAS ENTIDADES DE CRÉDITO ${ }^{1}$
}

\author{
Natalia Pérez Rivas \\ Profesora Ayudante Doctora de Derecho Penal \\ Universidad de Santiago de Compostela
}

Sumario: I. Introducción. II. Bien jurídico. III. El delito de financiación ilegal: contenido del injusto. 3.1. Tipo básico. 3.2. Tipo agravado. 3.2.1. Agravación por razón de la cuantía. 3.2.2. Agravación por financiación de origen extranjero. 3.3. Tipo hiperagravado. IV. Las atipicidades de la financiación delictiva de los partidos políticos en cuanto al objeto material: especial referencia a los créditos bancarios. 4.1. La condonación de deuda por las entidades bancarias. 4.2. La ausencia límites al endeudamiento de los partidos políticos. V. La publicidad de la información sobre los a los partidos políticos. VI. Conclusiones. Bibliografía

Resumen: Los partidos políticos españoles presentan una gran dependencia con respecto a las entidades de crédito con los consiguientes riesgos que ello comporta, en términos de injerencia en la conformación de la voluntad política. La ausencia de límite alguno en cuanto al endeudamiento bancario sigue representando el principal problema en el ámbito de la financiación de los partidos políticos. En el 2015 se procedió a reforma la Ley Orgánica 8/2007, de 4 de julio, sobre financiación de los partidos políticos a efectos de prohibir a los bancos efectuar condonaciones totales o parciales de deuda a los partidos políticos (art. 4.4). Por el contrario, ninguna previsión se contiene, a este respecto, en la regulación

\footnotetext{
1 Este trabajo se enmarca en el Proyecto de Investigación «Nuevos instrumentos jurídicos en la lucha contra la corrupción pública: propuestas desde el derecho penal y el derecho constitucional»(DER2015-71176-R), financiado por el Ministerio de Economía y Competitividad y cofinanciado por el Fondo Europeo de Desarrollo Regional (FEDER) correspondiente al marco financiero plurianual 2014-2020.
} 
del delito de financiación ilegal de partidos políticos (art. 304 bis del Código Penal) pese a la conceptuación, de estas condonaciones, como donaciones encubiertas. De ello parece inferirse que, para el legislador, es preferible la dependencia de los partidos políticos respecto de los bancos sobre otros grupos económicos y de poder.

Palabras clave: partidos políticos, financiación ilegal, condonaciones de deuda, entidades de crédito, dependencia.

Abstract: Spanish political parties are highly dependent on credit institutions with the resulting risks, in terms of interference in shaping the political will. The absence of any limit on bank indebtedness remains the main problem in the area of financing political parties. In 2015, the Organic Act 8/2007 of $4^{\text {th }}$ July, on the financing of political parties was reformed to prohibit banks from making total or partial debt forgiveness to political parties (art. 4.4). On the contrary, no provision is made in this regard for regulating the offence of illegal financing of political parties (art. 304 bis Criminal Code) despite the conception of these condonations as covert donations. This suggest that for the legislator, the dependence of political parties on credit institutions over other economic and power groups, is preferable.

Keywords: political parties, illegal financing, debt forgiveness, credit institutions, reliance.

\section{Introducción}

La corrupción pública constituía, hasta septiembre de 2012, la quinta causa de preocupación de la población española según el barómetro del Centro de Investigaciones Sociológicas (CIS) ${ }^{2}$. Esta situación cambió, drásticamente, en febrero de 2013 situándose —a partir de ese momento y hasta enero de 2019- en el segundo motivo de inquietud por detrás del paro. Ello coincide temporalmente, entre otros, con el escándalo del caso Gürtel, la detención de Luis Bárcenas (tesorero del Partido Popular), el caso Púnica, el caso Palau, a lo que debe sumarse la grave crisis económica que, durante ese periodo, estaba sufriendo nuestro país.

2 Disponibles en: http://www.cis.es/cis/opencm/ES/11_barometros/index.jsp 
Fig. 1. Principales motivos de preocupación de la población española

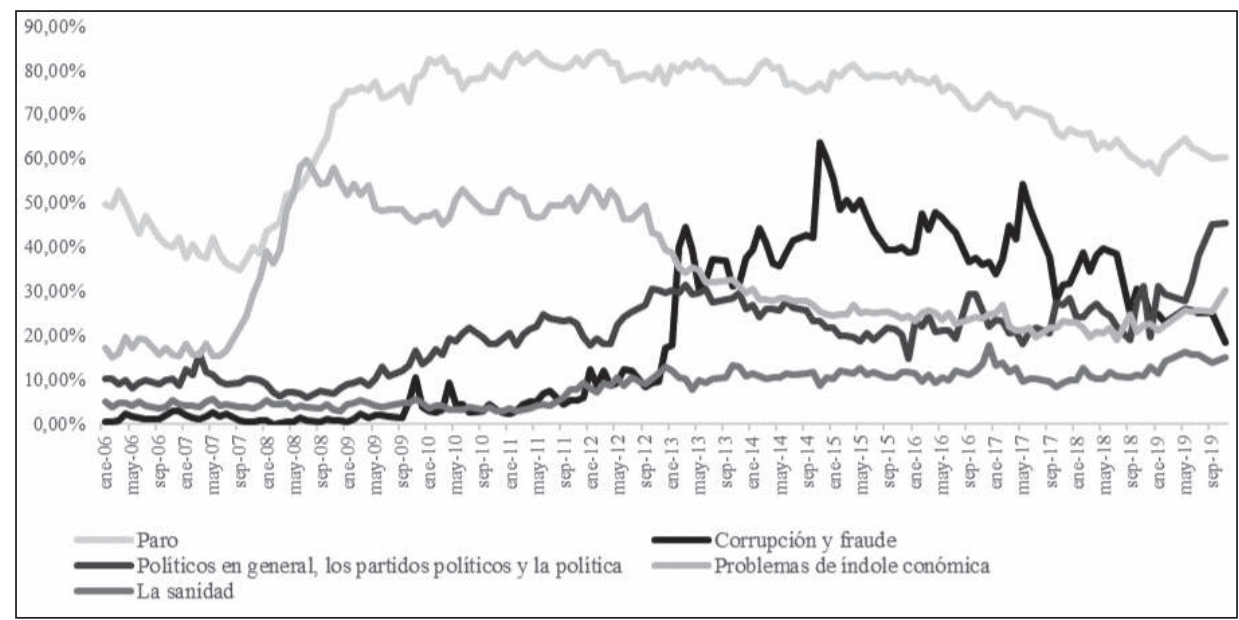

Fuente: Elaboración propia a partir de los barómetros del CIS (enero de 2006 a noviembre de 2019)

Los casos anteriormente mencionados se vinculan, todos ellos, a supuestos de financiación ilegal de los partidos políticos (PP y CiU, respectivamente), que constituye, como se denuncia en los informes del GRECO (2009), la principal forma de corrupción política en España (GUARDIOLA LAGO, 2018). Ello explica por qué los partidos políticos se erigen como el tercero - y, desde enero a noviembre de 2019, el segundo- de los motivos que genera una mayor preocupación entre la población española (CIS).

Esta realidad ha tenido su traslación al indicador de confianza en los partidos políticos cuyo promedio fue - durante el periodo comprendido entre enero de 2006 a noviembre de 2019- del 36,21\% (en una escala de ponderación en la que el 0 indica una valoración muy mala y el 100 refleja una impresión muy buena). A este respecto, los peores datos se registraron desde septiembre de 2012 a mayo de 2014, en el que el promedio del citado indicado se situó en $27,59 \%$, alcanzándose el mínimo histórico en febrero de $2013(23,80 \%)^{3}$.

3 Disponible en: http://www.cis.es/cis/export/sites/default/-Archivos/Indicadores/ documentos_html/IndiPol.html, [último acceso: 2020]. 
Fig. 2. Indicador de confianza en los partidos políticos

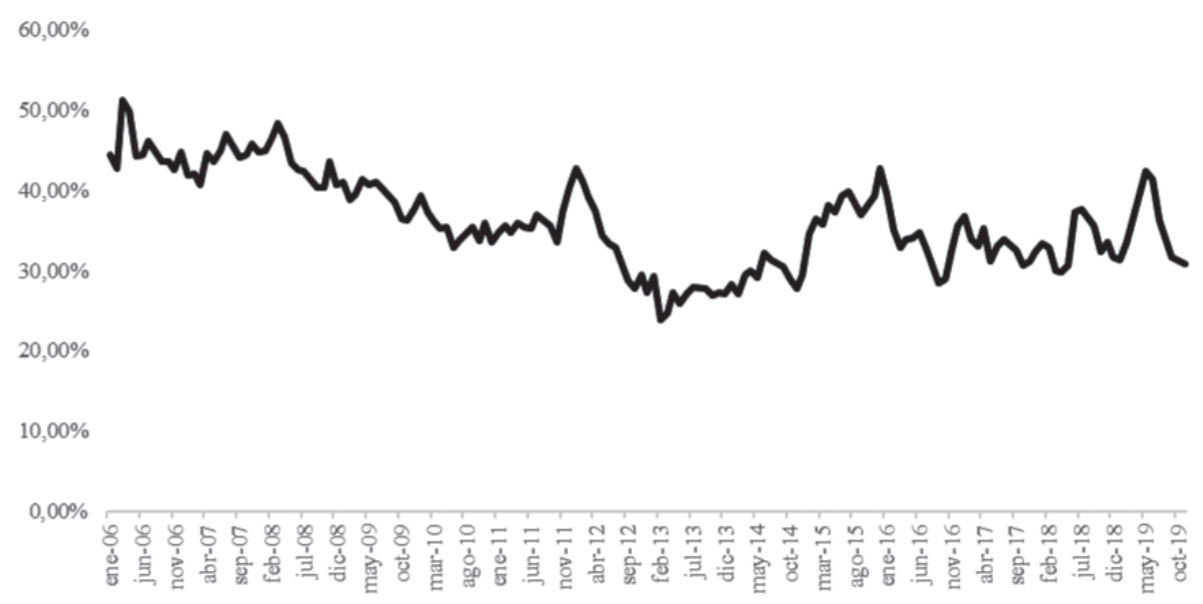

Fuente: Elaboración propia a partir de los datos del CIS (enero de 2006 a febrero de 2019)

Asimismo, estos hechos han repercutido negativamente en el Índice de Percepción contra la Corrupción (CPI) elaborado por Transparencia Internacional (TI ${ }^{4}$. Así, de conformidad con el CPI correspondiente al año 2017, España se sitúa, en el ámbito de la lucha contra la corrupción pública, en la posición 42 de los 180 países analizados. Si limitamos la comparativa a los 28 Estados miembro de la Unión Europea (UE), España se ubicó en el puesto 18, siendo solo superada por Bulgaria, Hungría, Grecia, Rumanía, Croacia, Italia, Eslovaquia y Malta. Entre 2006 y 2017, años en los que se anotaron, respectivamente, el mejor y el peor dato histórico, España descendió un total de 19 posiciones a nivel mundial y de 6 a nivel de la UE. En este sentido, en un estudio elaborado por la Comisión Europea en cuanto a la corrupción se constató que el 95\% de las personas encuestadas en España estimaban que la corrupción estaba ampliamente extendida en todo el país (COM (2014) 38 final) ${ }^{5}$.

4 Disponible en: https://transparencia.org.es/indice-de-percepcion-de-la-corrupcion/, [último acceso: 2020].

5 Informe de la Comisión al Consejo y al Parlamento Europeo sobre la lucha contra la corrupción en la UE [COM (2014) 38]. Disponible en https://ec.europa.eu/transparency/ regdoc/rep/1/2014/ES/1-2014-38-ES-F1-1.Pdf, [último acceso: 2020]. 
Fig. 3. Indicador de percepción contra la corrupción

\begin{tabular}{|c|c|c|c|c|c|c|c|c|}
\hline $\begin{array}{c}\text { Posición } \\
2006\end{array}$ & Países & Puntos & $\begin{array}{c}\text { Posición } \\
2012\end{array}$ & Puntos & \begin{tabular}{|c} 
Posición \\
2017
\end{tabular} & Puntos & $\begin{array}{c}\text { Variación } \\
\text { puntos }\end{array}$ & $\begin{array}{l}\text { Variación } \\
\text { puestos }\end{array}$ \\
\hline 1 & Finlandia & 96 & 1 & 90 & 3 & 85 & -9 & -2 \\
\hline 4 & Dinamarca & 95 & 1 & 90 & 2 & 88 & -7 & +2 \\
\hline 5 & Suecia & 92 & 4 & 88 & 6 & 84 & -8 & +1 \\
\hline 9 & Holanda & 87 & 9 & 84 & 8 & 82 & -5 & -1 \\
\hline 11 & Luxemburgo & 86 & 12 & 80 & 8 & 82 & -4 & -3 \\
\hline 11 & Reino Unido & 86 & 17 & 74 & 8 & 82 & -4 & -3 \\
\hline 11 & Austria & 86 & 25 & 69 & 13 & 75 & -9 & +2 \\
\hline 16 & Alemania & 80 & 13 & 80 & 12 & 81 & +1 & -4 \\
\hline 18 & Francia & 74 & 22 & 71 & 23 & 70 & -4 & +5 \\
\hline 18 & Irlanda & 74 & 25 & 69 & 19 & 74 & $=$ & +1 \\
\hline 20 & Bélgica & 73 & 16 & 75 & 16 & 75 & +2 & -4 \\
\hline 23 & España & 68 & 30 & 65 & 42 & 57 & -9 & +19 \\
\hline 24 & Estonia & 67 & 32 & 64 & 21 & 71 & +4 & -3 \\
\hline 26 & Portugal & 66 & 33 & 63 & 29 & 63 & -3 & +3 \\
\hline 28 & Eslovenia & 64 & 37 & 61 & 34 & 61 & -3 & +6 \\
\hline 28 & Malta & 64 & 43 & 57 & 46 & 56 & -8 & +18 \\
\hline 37 & Chipre & 56 & 29 & 66 & 42 & 57 & +1 & +5 \\
\hline 41 & Hungría & 52 & 46 & 55 & 66 & 45 & -7 & +25 \\
\hline 45 & Italia & 49 & 72 & 42 & 54 & 50 & +1 & +9 \\
\hline 46 & Lituania & 48 & 48 & 54 & 38 & 59 & +11 & -12 \\
\hline 46 & Rep. Checa & 48 & 54 & 49 & 42 & 57 & +9 & -4 \\
\hline 49 & Letonia & 47 & 54 & 49 & 40 & 58 & +11 & -9 \\
\hline 49 & $\begin{array}{c}\text { Rep. } \\
\text { Eslovaquia }\end{array}$ & 47 & 62 & 46 & 54 & 50 & +3 & +5 \\
\hline 54 & Grecia & 44 & 94 & 36 & 59 & 48 & +4 & +5 \\
\hline 57 & Bulgaria & 40 & 75 & 41 & 71 & 43 & +3 & +14 \\
\hline 61 & Polonia & 37 & 41 & 58 & 36 & 60 & +23 & -25 \\
\hline 69 & Croacia & 34 & 62 & 46 & 57 & 49 & +15 & -12 \\
\hline 84 & Rumanía & 31 & 66 & 44 & 59 & 48 & +17 & -25 \\
\hline
\end{tabular}

Fuente: Elaboración propia a partir de los datos de Transparencia Internacional 
No es de extrañar pues que, constatada esta realidad, el gobierno del Partido Popular procediese a articular, en septiembre de 2013, el llamado «Plan de Regeneración Democrática» ${ }^{6}$. Dicho plan contenía un total de 40 medidas dirigidas a «luchar contra la corrupción y mejorar los mecanismos de respuesta y detección de que dispone el ordenamiento jurídico» las cuáles se dividían en tres paquetes normativos: a) el control de la actividad económica de los partidos; b) la regulación del ejercicio de cargo público de la Administración General del Estado; c) la respuesta penal contra la corrupción. Pues bien, en el marco de este último paquete normativo se abordó la conveniencia de tipificar, en tanto que mal endémico (REBOLLO VARGAS, 2018), la financiación ilegal de los partidos políticos. Finalmente, esta iniciativa se plasmó en el art. 304 bis CP introducido por la Ley Orgánica 1/2015, de 30 de marzo, por la que se modifica la Ley Orgánica 10/1995, de 23 de noviembre, del Código Penal (en adelante LO 1/2015). No obstante, pese a lo loable de esta iniciativa, lo cierto es que el legislador ha perdido una gran oportunidad para luchar de forma eficiente contra esta forma de corrupción política. Como tendremos ocasión de comprobar a lo largo de nuestra exposición, su regulación legal es incompleta y técnicamente deficiente. Claro ejemplo de ello son las incomprensibles lagunas punitivas de que adolece el tipo, que no hacen más que evidenciar la resistencia que presentan los partidos políticos a dotarse de mecanismos de autorregulación. De entre ellas, nuestra atención se centrará en las que afectan a su objeto material y, más concretamente, en la relativa a las condonaciones de las deudas crediticias $^{7}$.

\section{Bien jurídico}

La ubicación sistemática de un concreto tipo delictivo en la estructura del Libro II del Código Penal suele ser utilizada como indicador del bien jurídico que con su regulación se tutela. En ese sentido, el tipo analizado se contempla en el Título XIII bis situándose, por tanto, entre los delitos contra el patrimonio y el orden socioeconómico y los delitos contra la hacienda y la seguridad social. Este hecho parece dotar al bien jurídico tutelado por este delito de un componente eminentemente economicista y privado (NÚÑEZ CASTAÑO, 2017b; REBOLLO VARGAS, 2018). No obstante, esta interpretación tiene un difícil encaje entre las razones alegadas por el legislador en la Exposición de Motivos de la LO

\footnotetext{
Disponible en: https://www.lamoncloa.gob.es/consejodeministros/Paginas/ enlaces/200913Enlace_Regeneraci\%C3\%B3nDemocr\%C3\%A1tica.aspx, [último acceso: 2020].

7 Sobre la regulación del delito de financiación ilegal de partidos políticos véase, PÉREZ RIVAS (2019) y bibliografía allí citada.
} 
$1 / 2015$, que justifican su tipificación en la necesidad de reforzar la lucha contra la corrupción pública.

En efecto, de conformidad con lo preceptuado en el art. $6 \mathrm{CE}$, los partidos políticos son una expresión del pluralismo político en la medida en que concurren a la formación y manifestación de la voluntad popular, siendo el instrumento fundamental de participación política de los ciudadanos en los asuntos públicos. Estamos de acuerdo en que, en atención a lo transcendente de la función representativa que están llamados a desempeñar en nuestro Estado social y democrático de derecho, es necesario evitar, en su ejercicio, injerencias externas que busquen favorecer intereses meramente privados (NUÑEZ CASTAÑO, 2017a y 2015; DE LA MATA BARRANCO, 2016; MUÑOZ CUESTA, 2015; OLAIZOLA NOGALES, 2015b; SÁINZ-CANTERO CAPARRÓS, 2015) que distorsionen la voluntad popular y quebranten, en consecuencia, la confianza de los ciudadanos en el actual sistema político y democrático (NUÑEZ CASTAÑO, 2017b; CORCOY BIDASOLO / GALLEGO SOLER, 2015). Por otro lado, la existencia de un régimen de financiación justo y transparente resulta clave para minimizar las prácticas corruptas (GUARDIOLA LAGO, 2018; OLAIZOLA NOGALES, 2014) y garantizar, al mismo tiempo, la igualdad de oportunidades entre todas las fuerzas políticas (LEON ALAPONT, 2019a, 2019b y 2018; SIERRA LÓPEZ, 2017; BUSTOS RUBIO, 2016; DE LA MATA BARRANCO, 2016), siendo estos elementos los que caracterizan el correcto funcionamiento del sistema democrático de partidos políticos (NIETO MARTÍN, 2006). En este sentido, en nada difiere el poder de influencia corrupto sobre el devenir de las políticas públicas que ostenta el funcionario sobornado respecto del que puede tener el dirigente de un partido político financiado ilegalmente, especialmente si este detenta el gobierno de la nación (ODRIOZOLA GURRUTXAGA, 2018; JAVATO MARTÍN, 2017). Por otro lado, resulta claro que aquellos partidos políticos que tienen mayores recursos financieros -legales e ilegales- parten de una situación de ventaja en la contienda política que les permiten, entre otras actuaciones, el diseño de grandes campañas publicitarias orientadas a su visibilidad y a la captación de votos (REBOLLO VARGAS, 2018) que redundarán, finalmente, en la obtención de un mayor número de escaños. Es, permítaseme la expresión, un supuesto de «dopaje político» que dinamita los principios de igualdad, de transparencia de la financiación y, en última instancia, el pluralismo político y la función representativa de los partidos políticos.

En nuestra opinión, con la regulación del delito de financiación ilegal de los partidos políticos se pretende tutelar el normal desarrollo de las funciones constitucionalmente asignadas a los partidos políticos (MACÍAS ESPEJO, 2018 y 2016; REBOLLO VARGAS, 2018; JAVATO MARTÍN, 2017; OLAIZOLA NOGALES, 2015a, 2015b y 2015c; SÁINZCANTERO CAPARRÓS, 2015) frente a todo elemento que introduzca alguna distorsión entre la voluntad popular y el ejercicio del poder político, a efectos de garantizar, el correcto funcionamiento de nuestro sis- 
tema democrático (ODRIOZOLA GURRUTXAGA, 2018: PUENTE ABA, 2017 y 2015; NUÑEZ CASTAÑO, 2017a y 2017b; CORCOY BIDASOLO / GALLEGO SOLER, 2015; MAROTO CALATAYUD, 2015a y 2015b; NIETO MARTÍN, 2006), tenga o no una trascendencia exterior inmediata (ODRIOZOLA GURRUTXAGA, 2018; NÚÑEZ CASTAÑO, 2017b).

En atención a ello, desde ciertos sectores doctrinales, a los que nos sumamos, se aboga por una modificación de su ubicación sistemática a efectos de situarlo en el marco de los delitos contra la Administración Pública (JAVATO MARTÍN, 2017 y 2015; MUÑOZ CONDE, 2015; PRECIADO DOMĖNECH, 2015) ${ }^{8}$ o, más adecuado en nuestra opinión, los relativos a la Constitución en tanto que los partidos políticos son conceptuados, como ya hemos dicho, un instrumento esencial para el desarrollo del Estado social y democrático de derecho (MAROTO CALATAYUD, 2015a; MUÑOZ CONDE, 2015; SÁINZ-CANTERO CAPARRÓS, 2015).

\section{El delito de financiación ilegal: contenido del injusto}

El objeto material del delito de financiación ilegal de los partidos políticos se centra, exclusivamente, en una concreta modalidad de financiación de los partidos políticos: la financiación ordinaria privada mediante donaciones y aportaciones ${ }^{9}$. Durante el periodo comprendido entre los años 2007 a 2015, estos ingresos representaron el 2,49\% de la totalidad de los recursos de los partidos políticos.

8 Esta era la propuesta defendida, durante la tramitación parlamentaria de la reforma del Código Penal de 2015, por los grupos parlamentarios de UPyD -el cual propuso situarlo entre los delitos contra la administración pública, como un nuevo Capítulo XI del Título XIX, inmediatamente después de los delitos de corrupción en las transacciones internacionales y el Grupo Parlamentario Mixto -el cual sugirió introducirlos como arts. 422 bis y ter, entre los delitos contra la administración pública, pero vinculado al delito de cohecho y a la aceptación de regalos.

9 De otra opinión, LEÓN ALAPONT (2019a, 2019b y 2018) que incluye en el tipo penal tanto la financiación ordinaria como la electoral. 


\section{Fig. 4. Recursos que integran la financiación de los partidos políticos}

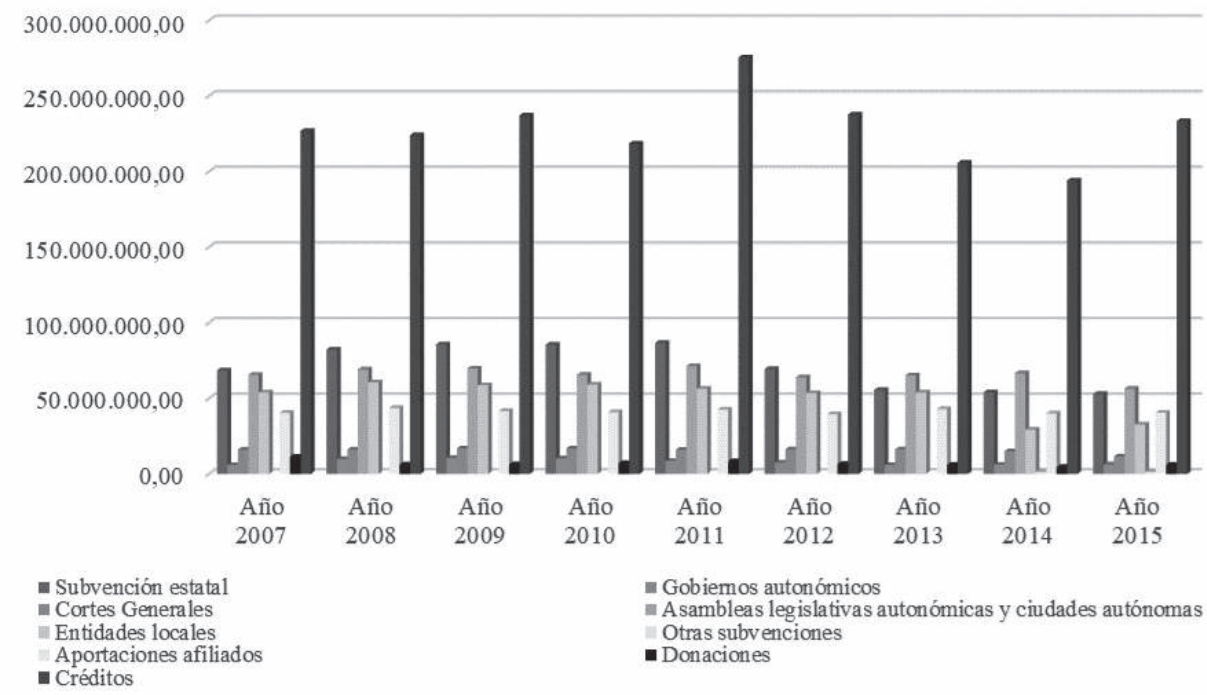

Fuente: Elaboración propia a partir de los datos reflejados en los Informes del Tribunal de Cuentas de fiscalización de los estados contables de los partidos políticos y de las aportaciones percibidas por las fundaciones y asociaciones vinculadas orgánicamente, ejercicios 2007 a 2015.

\subsection{Tipo básico}

De conformidad con el art. 4 Uno de la Ley Orgánica 8/2007, de 4 de julio, sobre financiación de los partidos políticos (en adelante LO 8/2007), los partidos políticos podrán recibir, de acuerdo con sus estatutos, cuotas y aportaciones de sus afiliados así como donaciones no finalistas - es decir, no destinadas a un proyecto en concreto-, o nominativas (en dinero o en especie) procedentes de personas físicas, siempre dentro de los límites y de acuerdo con los requisitos y las condiciones establecidos en ella. A este respecto, las donaciones dinerarias deberán abonarse en cuentas abiertas en entidades de crédito exclusivamente para dicho fin, debiendo quedar constancia, en todo caso, de la fecha de su imposición, su importe y del nombre e identificación fiscal del donante. Por lo que respecta a las donaciones en especie, se entenderán aceptadas mediante certificación expedida por el partido político en la que se haga constar, además de la identificación del donante, el documento público u otro documento auténtico que acredite la entrega del bien donado haciendo mención expresa de su carácter irrevocable.

Por el contrario, no podrán aceptar o recibir, directa o indirectamente, las donaciones privadas que a continuación se detallan (art. 5 Uno LO 
8/2007): a) donaciones anónimas, finalistas —financiación corrupta por antonomasia - o revocables; b) donaciones procedentes de una misma persona física (nacional o extranjera) superiores a los $50.000 €$ anuales (art. 7 Uno LO 8/2007). Se exceptúan de este límite, no obstante, las donaciones en especie de bienes inmuebles, siempre que estas sean aceptadas mediante certificación expedida por el partido político en la que se haga constar, además de la identificación del donante, el documento público u otro documento auténtico que acredite la entrega del bien donado haciendo mención expresa del carácter irrevocable de la donación; c) donaciones procedentes de personas jurídicas y de entes sin personalidad jurídica.

\section{Fig. 5. Evolución de las donaciones privadas a los partidos políticos}

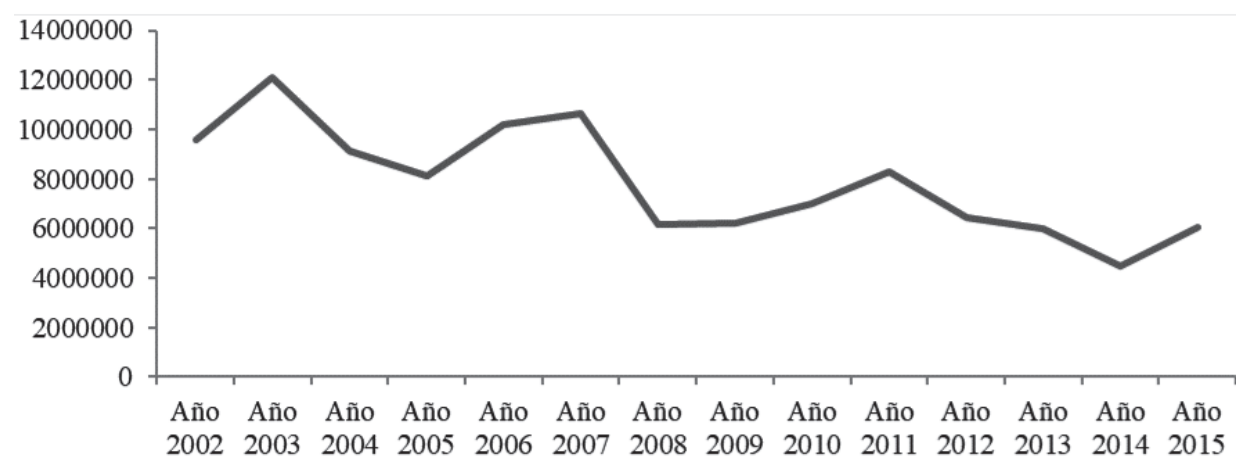

Fuente: Elaboración propia a partir de los datos reflejados en los Informes del Tribunal de Cuentas de fiscalización de los estados contables de los partidos politicos y de las aportaciones percibidas por las fundaciones y asociaciones vinculadas orgánicamente, ejercicios 2002 a 2015.

Pues bien, el art. 304 bis. 1 CP remite, en bloque, a lo dispuesto en esos arts. 5. Uno y 7. Uno LO 8/2007 a efectos de determinar el contenido del injusto del tipo básico del delito de financiación ordinaria privada ilegal, tanto en su modalidad pasiva - recibir- como en su modalidad activa - entregar-. Ello conlleva elevar a la categoría de delito una mera infracción administrativa sin exigir, para ello, ningún elemento adicional de lesividad (OLAIZOLA NOGALES, 2015c). Se produce, en consecuencia, un «solapamiento exacto» entre ambas regulaciones (MAROTO CALATAYUD, 2015a y 2015b). Ante esta realidad, la doctrina discute si, en el caso de infracción de los dispuesto en el art. 5. Uno LO 8/2007, deberá aplicarse una sanción administrativa (art. 17 bis. Dos. a LO 8/2007) o, por el contrario, una sanción penal (art. 304 bis CP), al no constar, en la redacción del tipo penal, ningún criterio de delimitación. Esta circunstancia que ha llevado a algún autor a abogar por la supresión del tipo básico de la financiación ilegal pasiva (OLAIZOLA NOGALES, 2015b y 2015c). 
No obstante, lo cierto es que el propio art. 17. Uno LO 8/2007 viene a dar respuesta a esta cuestión al disponer que «[...] el Tribunal de Cuentas acordará la imposición de sanciones al partido político que cometa alguna de las infracciones que se tipifican en este artículo, siempre que no constituyan delito». Es decir, cuando los comportamientos regulados en la LO 8/2007 den lugar a la comisión de una infracción administrativa y un ilícito penal, el sujeto será sancionado por esta última vía (LEÓN ALAPONT, 2019a; MACÍAS ESPEJO, 2016). En todo caso, hubiera sido preferible, siguiendo la propuesta un cierto sector doctrinal, el establecimiento de límites cuantitativos distintos para la infracción administrativa y para el delito, lo que dotaría a este de una lesividad propia (JAVATO MARTÍN, 2017 y 2016; MACÍAS ESPEJO, 2016; OLAIZOLA NOGALES, 2015b).

\subsection{Tipo agravado}

\subsubsection{Agravación por razón de la cuantía}

El art. 304 bis. 2 a) CP contempla una agravación, por razón de la cuantía, en un doble supuesto: a) cuando las donaciones recogidas en las letras a) y c) del art. 5.Uno LO 8/2007 —las donaciones anónimas, finalistas o revocables así como las donaciones procedentes de personas jurídicas y de entes sin personalidad jurídica - sean de un importe superior a los $500.000 €$; b) cuando las donaciones procedentes de una misma persona sean superiores a los $550.000 €$ anuales.

Este tipo agravado resultará también de aplicación a las donaciones realizadas por personas físicas extranjeras que superen las cuantías a las que hemos hecho mención (art. 7. Uno LO 8/2007). A este respecto, NÚNEZ CASTAÑO (2017 y 2015) señala que se trata esta de «una posibilidad que determina una interpretación extensiva muy cuestionable que supondrá una nueva vulneración del principio de legalidad. Quizás lo inaceptable de la posible atipicidad de estos comportamientos, permita recurrir a una interpretación amplia de la norma que solucione la laguna que ha creado el legislador, pero, en mi opinión, una mala técnica legislativa no puede ni debe solucionarse mediante la infracción del principio de legalidad». Por el contrario, MAROTO CALATAYUD (2015a y 2015b) considera que este supuesto se incluye en el ámbito de aplicación del tipo agravado por financiación extranjeras (art. 304 bis. 2 CP).

La razón de ser de esta agravación radica en que, dado el montante donado, la capacidad de influencia en la voluntad del partido se incrementa de forma notable (OLAIZOLA NOGALES, 2015a y 2015c). No obstante, llama la atención lo elevado de la cuantía exigida para proceder a la agravación del tipo, que representa diez veces la cantidad máxima permitida por la LO 8/2007 (MAROTO CALATAYUD, 2015a y 2015b). 
Por otro lado, el precepto no aclara, a efectos de aplicar esta agravante, si la donación ha de alcanzar esa cuantía en una única entrega o si, por el contrario, pueden acumularse las diversas donaciones realizadas a lo largo de un determinado periodo temporal (un año natural). Una interpretación coherente con la disposición contenida en el art. 5.1.b) LO 8/2007 nos lleva a defender la segunda de las interpretaciones expuestas (PUENTE ABA, 2017; NÚÑEZ CASTAÑO, 2017a y 2017b; MAROTO CALATAYUD, 2015b). En todo caso, sería deseable una mayor concreción por parte del legislador a este respecto.

\subsubsection{Agravación por financiación de origen extranjero}

Asimismo, de conformidad con el art. 7. Dos LO 8/2007, «los partidos no podrán aceptar ninguna forma de financiación por parte de Gobiernos y organismos, entidades o empresas públicas extranjeras o de empresas relacionadas directa o indirectamente con los mismos». En caso de hacerlo, esa conducta será constitutiva, únicamente, de una infracción administrativa muy grave (art. 17 Dos. a LO 8/2007) por cuya comisión se impondrá un importe que irá del doble al quíntuplo de la cantidad que exceda del límite legalmente permitido (art. 17 bis Uno. a LO 8/2007). A este respecto, un cierto sector de la doctrina critica que, en atención a la trascendencia que pudieran tener estas concretas donaciones, no se hayan incluido en el ámbito objetivo del tipo básico del delito de financiación ilegal (SIERRA LÓPEZ, 2017; MUÑOZ CUESTA, 2015; SÁINZCANTERO CAPARRÓS, 2015). No obstante, si esa donación supera los $100.000 €$ la conducta será constitutiva de un delito de financiación ilegal de partidos políticos (art. 304 bis. 2 b CP). En todo caso, no estaríamos en presencia, en nuestra opinión, de un tipo agravado, sino que se trataría, más bien, del tipo básico de financiación ilegal extranjera (JAVATO MARTÍN, 2017 y 2016; MAROTO CALATAYUD, 2015b).

\subsection{Tipo hiperagravado}

El art. 304 bis. 3 CP contempla un tipo hiperagravado que resultará de aplicación en aquellos casos en los que los hechos regulados en el apartado 2 revistan una «especial gravedad». Sin embargo, el legislador no ha establecido un criterio interpretativo que permita determinar qué supuestos tienen cabida en dicha cláusula agravatoria ${ }^{10}$. Ello supone una

10 Ello a diferencia de lo que ocurre, por ejemplo, en el caso de los delitos de corrupción privada, disponiéndose en el art. 286 quater $\mathrm{CP}$ que «si los hechos a que se refieren los artículos de esta Sección resultaran de especial gravedad, se impondrá la pena en su mitad superior, pudiéndose llegar hasta la superior en grado. Los hechos se considerarán, en todo caso, de especial gravedad cuando: a) el beneficio o ventaja tenga un valor especialmente 
flagrante vulneración del principio de legalidad que deja en manos de los órganos judiciales, una vez más, la labor de clarificar su significado.

De forma mayoritaria, la doctrina estima que la concurrencia de esta circunstancia vendrá determinada, principalmente, por la especial significancia o relevancia económica de la donación o aportación realizada con relación límites señalados en el art. 304 bis. 2 CP, en tanto que único criterio tenido en cuenta por el legislador para tipificar las conductas agravadas (ODRIOZOLA GURRUTXAGA, 2018; JAVATO MARTÍN, 2017 y 2015; NÚÑEZ CASTAÑO, 2017a, 2017b, 2015; PUENTE ABA, 2017 y 2015; BUSTOS RUBIO, 2016; OLAIZOLA NOGALES, 2015a, 2015b y 2015c). Desde otras posiciones se considera, por el contrario, que también podrían ser objeto de valoración, a tal efecto, factores tales como «la condición o circunstancias del sujeto activo siempre que ello no derive en la posible apreciación de otra infracción penal», «los términos o condiciones en que se realiza la donación», "cuando la acción del autor no sea meramente ocasional», entre otros (SIERRA LÓPEZ, 2017; SÁINZCANTERO CAPARRÓS, 2015). Tendremos que esperar, como hemos señalado, a lo que determinen, en su momento, los órganos judiciales.

\section{Las atipicidades de la financiación delictiva de los partidos políticos en cuanto al objeto material: especial referencia a los créditos bancarios}

En efecto, los supuestos contemplados en el art. 304 bis CP lesionan, de forma clara, el bien jurídico objeto de tutela sobre la base de la captación de la voluntad del partido político que ello puede conllevar por parte terceros (MACÍAS ESPEJO, 2018 y 2016; JAVATO MARTÍN, 2017; NÚÑEZ CASTAÑO, 2017a y 2017b; PUENTE ABA, 2017 y 2015; MAROTO CALATAYUD, 2015a y 2015b; OLAIZOLA NOGALES, 2015a, 2015b, 2015c y 2014; PRECIADO DOMĖNECH, 2015; SÁINZ-CANTERO CAPARRÓS, 2015). En este sentido, es claro que con ello se trate de controlar "que no sean las grandes corporaciones empresariales o lobbies concretos los que mediaticen y direccionen la verdadera actividad política de los partidos» (ORDÓÑEZ PÉREZ, 2012).

Pero no es menos cierto que todos los casos de financiación ilegal alteran el normal desarrollo de la función representativa encomendada a los partidos políticos y, en determinados supuestos, incluso de forma más relevante que los concretos comportamientos tipificados en el art. 304 bis CP (ODRIOZOLA GURRUTXAGA, 2018; REBOLLO VARGAS,

elevado, b) la acción del autor no sea meramente ocasional, c) se trate de hechos cometidos en el seno de una organización o grupo criminal, o d) el objeto del negocio versara sobre bienes o servicios humanitarios o cualesquiera otros de primera necesidad». 
2018; NÚÑEZ CASTAÑO, 2017; PUENTE ABA, 2017 y 2015; BUSTOS RUBIO, 2016; CORCOY BIDASOLO / GALLEGO SOLER, 2015; DE MIGUEL BERIAIN, 2015; MAROTO CALATAYUD, 2015a y 2015b). Por ello, no se entiende que el legislador haya dejado al margen de la tipificación penal el resto de fuentes de financiación - públicas y privadas- de los partidos políticos, generando con esa forma de proceder numerosas lagunas de punibilidad que siguen habilitando al mundo económico para influir, de forma decisiva, sobre el devenir de las políticas públicas (LEÓN ALAPONT, 2019a, 2019b y 2018; MUÑOZ CONDE, 2019; REBOLLO VARGAS, 2018; PUENTE ABA, 2017 y 2015; MACÍAS ESPEJO, 2016; MAROTO CALATAYUD, 2015a y 2015b; OLAIZOLA NOGALES, 2015b; PRECIADO DOMÈNECH, 2015). En esta misma línea se concluye por la Comisión de la Calidad Democrática, contra la corrupción y para las reformas institucionales y legales del Congreso de los Diputados (2018) que «es necesario reformar el artículo 304 bis del Código Penal, que actualmente dispone que cualquier infracción del artículo 5.1 de la Ley de Financiación de Partidos Políticos tiene la condición de delito, pues esta remisión resulta imprecisa y puede dejar fuera algunas conductas que deberían ser punibles en vía criminal». Preocupante es, a este respecto, la dependencia económica que los partidos políticos presentan, todavía, respecto de las entidades bancarias. Eb este sentido, resulta «inexplicable»—si nos circunscribimos al estricto ámbito jurídico-que no se haya procedido a la expresa tipificación de la conducta consiste en la condonación a aquéllos de sus deudas crediticias (LEÓN ALAPÓNT, 2019a, 2019b y 2018; ODRIOZOLA GURRUTXAGA, 2018; REBOLLO VARGAS, 2018; JAVATO MARTÍN, 2017; NÚÑEZ CASTAÑO, 2017; PUENTE ABA, 2017; BUSTOS RUBUIO, 2016; MAROTO CALATAYUD, 2015b; OLAIZOLA NOGALES, 2015c).

\subsection{La condonación de deuda por las entidades bancarias}

La financiación de los partidos políticos a través de créditos de las entidades bancarias se ha caracterizado por la "permisividad y (la) opacidad» (SANJURJO RIVO, 2018). Así, la Ley Orgánica 3/1987, de 2 de julio, sobre financiación de los partidos políticos (en adelante LO 3/1987) no hacía referencia alguna al tratamiento de las deudas con las entidades crediticias. Por su parte, la Disposición Transitoria Segunda de la LO 8/2007 establecía, en su versión original, que los acuerdos respecto de las condiciones de la deuda serán los admitidos según los usos y costumbres de tráfico mercantil habitual entre las partes. Con esta previsión, el legislador estaba dando una cobertura legal expresa a las prácticas condonatorias de la deuda crediticia que, en este ámbito, ya venían desarrollándose, de forma regular, desde tiempo atrás (PAJARES MONTOLÍO, 2016). A este respecto el Tribunal de Cuentas cifró el importe de las condonaciones que tuvieron lugar entre los años 1993 y 2002 en 25,4 
millones de euros (Tribunal de Cuentas, 2002). Si bien de tales acuerdos debía darse cuenta al Tribunal de Cuentas y al Banco de España, lo cierto es que dicha comunicación nunca se hizo efectiva al no especificarse, en la mencionada disposición legal, quién debía remitir esa información.

Claramente se trataba esta de una vía que los partidos políticos podían utilizar, lícitamente, para evitar los límites legales que se predicaban respecto de las aportaciones privadas constituyendo, en la práctica, donaciones encubiertas (ALMAGRO CASTRO, 2015; RUIZ-RICO RUIZ, 2014; SÁNCHEZ MUÑOZ, 2015; COELLO PORTUGAL, 2012; GRECO 2011 y 2009; HOLGADO GONZÁLEZ, 2003).

A ello se suma el hecho de que a través de estas condonaciones se puede producir «una desviación significativa del principio de igualdad que debe garantizar la equivalencia de oportunidades en la competición política, ya que previsiblemente la condonación de deudas bancarias puede llegar a favorecer a los partidos que ideológicamente se sitúen en posiciones más cercanas a los intereses económicos de esas entidades de crédito» (RUIZ-RICO RUIZ, 2015 y 2014) o a que, en todo caso, detentes mayores recursos financieros para el desarrollo de sus actividades (ALMAGRO CASTRO, 2015).

La evidencia de esta realidad llevó a que, en la reforma operada en 2012, se limitase —en virtud de la enmienda núm. 17 formulada por UPyD - la condonación de deuda a los partidos políticos a la cuantía de $100.000 €$ anuales, para cuyo cálculo se tendría en cuenta tanto las condiciones del principal de la deuda como de los intereses pactados. Nótese que esta cifra venía a coincidir con cantidad máxima que, anualmente, podía ser donada por una misma persona física o jurídica.

En la actualidad, estos acuerdos con las entidades financieras están sometidas a dos límites introducidos, en el art. 4.4 LO 8/2007, por la reforma operada a través de la Ley Orgánica 3/2015, de 30 de marzo, de control de la actividad económico-financiera de los partidos políticos (en adelante LO 3/2015). Así, por un lado, el tipo de interés que se aplique o, en su caso, se renegocie, no puede ser inferior al que corresponda a las condiciones de mercado; por otro, se han prohibido las condonaciones totales o parciales de deuda a los partidos políticos de forma pareja a lo que ha ocurrido respecto de las donaciones de las personas jurídicas.

Pese a lo loable de esta previsión, lo cierto es que son varias las críticas que se pueden efectuar a la misma. En primer lugar, se deja abierta la posibilidad de que se proceda a la cancelación no ya de la deuda en sí misma, sino de la garantía subyacente (Informe de la Subcomisión relativa al régimen y la financiación de los partidos políticos, 2018) ${ }^{11}$.

11 Informe de la Subcomisión relativa al régimen y la financiación de los partidos políticos (BOCG, 22 de marzo de 2018, núm. 323). 


\section{Fig. 6. Evolución comparativa de la deuda personal y la deuda hipotecaria de los partidos políticos con las entidades de crédito}

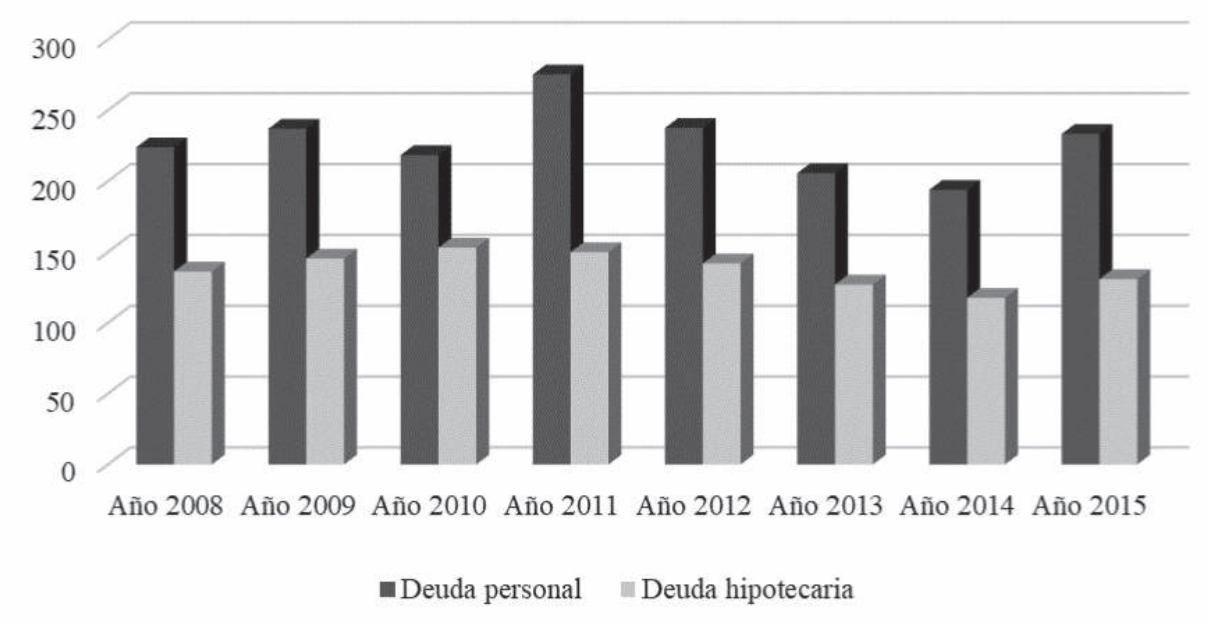

Fuente: Elaboración propia a partir de los datos reflejados en el Informe del Tribunal de Cuentas de fiscalización de los estados contables de los partidos politicos y de las aportaciones percibidas por las fundaciones y asociaciones vinculadas orgánicamente, ejercicios 2008 a 2015.

Tampoco se prevé su aplicación a los préstamos procedentes de otras fuentes distintas de las entidades de crédito, tales como particulares, sociedades u otras entidades legales (Informe de la Subcomisión relativa al régimen y la financiación de los partidos políticos, 2018) ${ }^{12}$. Y, finalmente, se han detectado supuestos en los que el partido político no llega a liquidar estos créditos al proceder al impago de la deuda vencida de forma indefinida lo que supone, de facto, su cancelación, sin que los bancos soliciten, por otro lado, su ejecución ${ }^{13}$. Concretamente, la deuda vencida alcanzó en el periodo analizado (2001 a 2015) su cifra más eleva-

12 Idem

13 A este respecto, el Tribunal de Cuentas en su «Informe de fiscalización de los estados contables de los partidos políticos y de las aportaciones percibidas por las fundaciones y asociaciones vinculadas orgánicamente, ejercicios 2014 y 2015» (BOE, 26 de abril de 2018, núm. 101), ponía de relieve como la formación política Eusko Alkartasuna (EA) «mantenía una deuda vencida hace más de 20 años correspondiente a cuatro operaciones con una misma entidad financiera, con un saldo contable de 814.717,32 €, de los que $620.633,43 €$ corresponden al principal y $194.083,89 €$ a intereses vencidos y no pagados», procediendo, en el ejercicio 2015, «a dar de baja en contabilidad la totalidad de esta deuda». 
da en el año 2002 (38,1 millones de euros) situándose, a 31 de diciembre de 2015, en 11,04 millones de euros ${ }^{14}$.

\section{Fig. 7. Evolución de la deuda vencida de los partidos políticos}

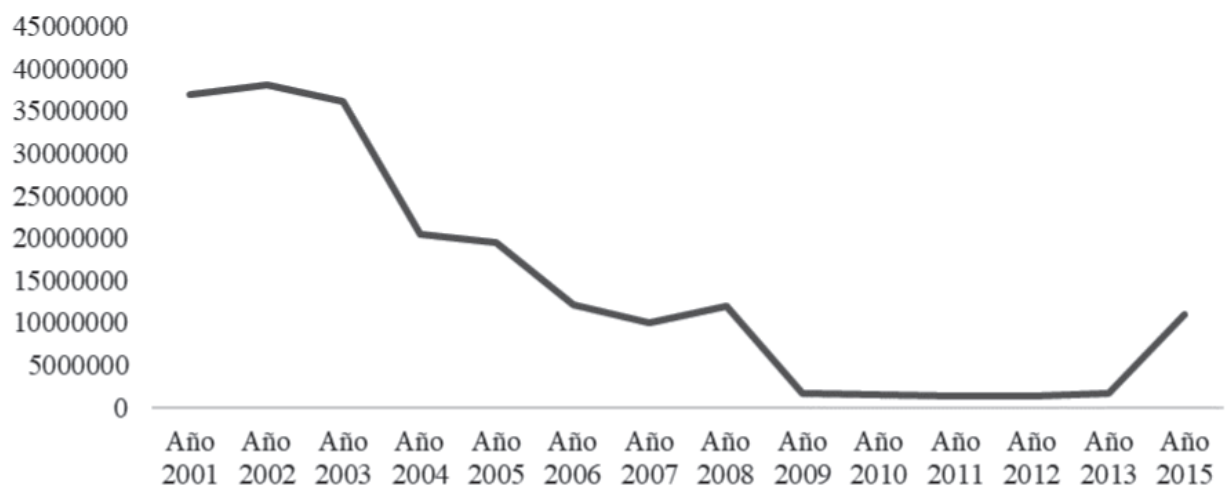

Fuente: Elaboración propia a partir de los datos reflejados en el Informe del Tribunal de Cuentas de fiscalización de los estados contables de los partidos políticos y de las aportaciones percibidas por las fundaciones y asociaciones vinculadas orgánicamente, ejercicios 2001 a 2015.

El Tribunal de Cuentas ha advertido sobre estas prácticas indicando la conveniencia de prohibirlas, de forma expresa, en la LO 8/2007 (Informe de la Subcomisión relativa al régimen y la financiación de los partidos políticos, 2018 ${ }^{15}$; TRIBUNAL DE CUENTAS, 2018).

\subsection{La ausencia de límites al endeudamiento de los partidos políticos}

Los partidos políticos presentan, como ya hemos dejado sentando, una fuerte dependencia económica respecto de las entidades financieras. Ello se ha visto favorecido por una regulación que ha pasado de una cierta restricción a la permisividad absoluta en cuanto al nivel de endeudamiento de los partidos políticos (ALMAGRO CASTRO, 2015). Así, la LO 3/1987 establecía que las amortizaciones anuales de los créditos contratados por los partidos políticos no podían superar el $25 \%$ de las

14 El importe de esta deuda vencida se distribuye, de la siguiente forma, entre estas formaciones políticas: Eusko Alkartasuna (0,81 millones de euros) y Unió Democrática de Catalunya (10,23 millones de euros).

15 Informe de la Subcomisión relativa al régimen y la financiación de los partidos políticos (BOCG, 22 de marzo de 2018, núm. 323). 
subvenciones públicas anuales concedidas por gastos generales y, en su caso, por funcionamiento de los grupos parlamentarios. Sin embargo, esta limitación despareció con la promulgación de la LO 8/2007 lo que, unido a la cobertura legal de los acuerdos de renegociación de la deuda, nos sitúa, irremediablemente, ante un escenario que favorece el sobreendeudamiento de los partidos políticos y, en consecuencia, su mayor dependencia respecto de los bancos. En el último informe presentado, el correspondiente al ejercicio del año 2015, el nivel de endeudamiento global de los partidos políticos se situaba en los 233,28 millones de euros. El 55,53\% de esa deuda correspondía, únicamente, a 4 partidos: PSOE $(27,13 \%), \operatorname{PP}(12,83 \%), \operatorname{PNV}(8,73 \%)$ y UDC $(6,84 \%)$.

\section{Fig. 8. Evolución de la deuda crediticia de los partidos políticos}

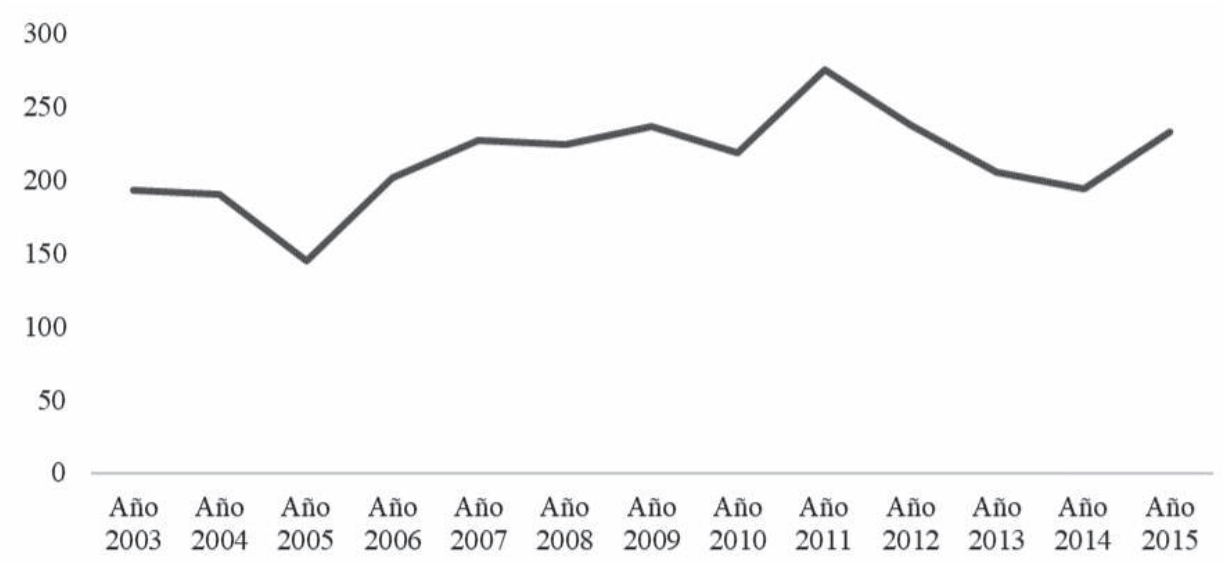

Fuente: Elaboración propia a partir de los datos reflejados en el Informe del Tribunal de Cuentas de fiscalización de los estados contables de los partidos politicos y de las aportaciones percibidas por las fundaciones y asociaciones vinculadas orgánicamente, ejercicios 2003 a 2015.

En la actualidad, los préstamos bancarios constituyen la principal fuente de financiación de los partidos políticos en España (ALMAGRO CASTRO, 2015; GRECO, 2009). Durante el periodo 2007 a 2015 los créditos de las entidades bancarias representaron el $82,73 \%$ de su financiación privada y el 46,82 \% del total de sus recursos económicos. Esta situación se ha visto más acusada desde el año 2011, como resultado del paulatino descenso experimentado por las subvenciones públicas a los partidos políticos tras la crisis económica ${ }^{16}$. Ello es una evidencia más, como pone de relieve SANJURJO RIVO (2018), del contradictorio queha-

16 En el año 2011 la deuda crediticia de los partidos políticos alcanzó los 275,3 millones de euros (TRIBUNAL DE CUENTAS, 2014). 
cer del legislador en esta materia ya que «mientras con una mano se reducen las posibles fuentes de financiación de los partidos, con la otra, en cambio, se abre - y mucho- otra u otras posibles vías de financiación».

\section{Fig. 9. Evolución comparativa fuentes de financiación de los partidos políticos}

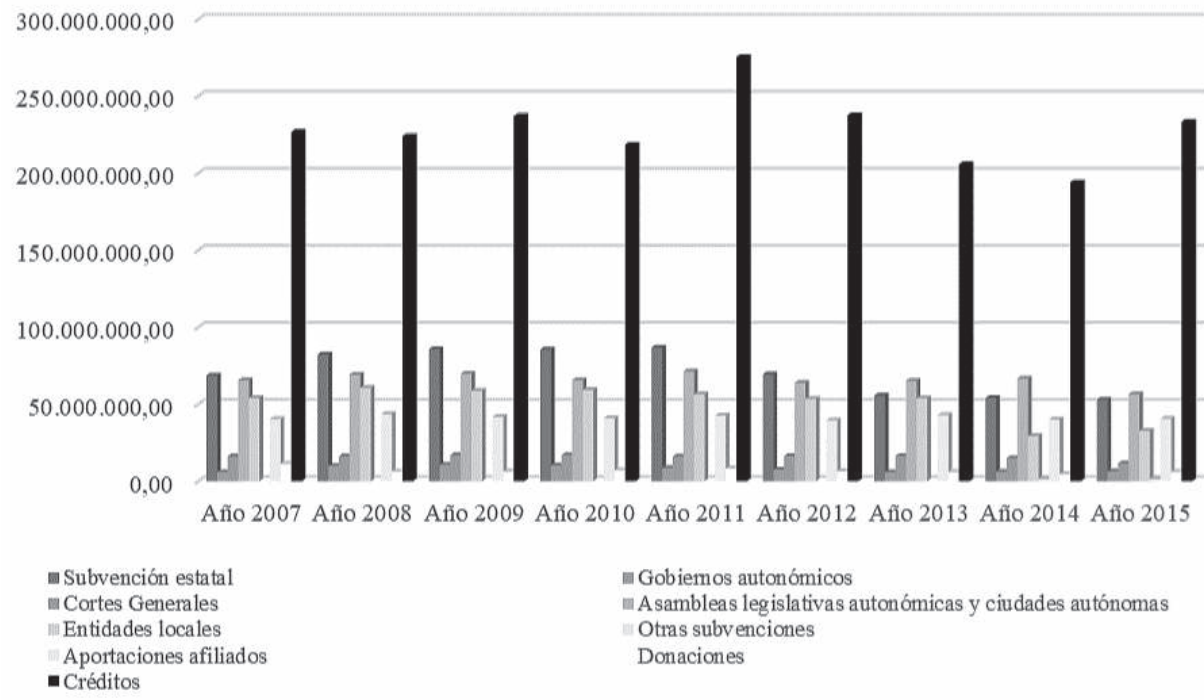

Fuente: Elaboración propia a partir de los datos reflejados en el Informe del Tribunal de Cuentas de fiscalización de los estados contables de los partidos políticos y de las aportaciones percibidas por las fundaciones y asociaciones vinculadas orgánicamente, ejercicios 2007 a 2015.

La falta de regulación legal de los términos y condiciones de los créditos bancarios sumado a la inexistencia de límite alguno a su cuantía -pese a las reiteradas peticiones, a este respecto, formulada por el GRECO (2016, 2015, 2013 y 2011) - tiene, como consecuencia lógica, una tendencia al sobreendeudamiento de los partidos políticos. En el año 2015, último del que tenemos información económica, el pasivo de las formaciones políticas analizadas sumaba un total de 412.553.129,86 $€$, procediendo el $58,63 \%$ de deudas con entidades de crédito. Si detallamos más pormenorizadamente nuestro análisis, observamos como el endeudamiento bancario de 13 (BNG, Chunta Aragonesista, CDC, Esquerra Republicana de Catalunya, Eusko Alkartasuna, Iniciativa per Catalunya Verds, IU, Nueva Canarias, Partido Aragonés, PNV, PSOE, PSC y UDC) de los 29 formaciones políticas estudiadas representa más del $80 \%$ del total de sus deudas. 
Fig. 10. Porcentaje de endeudamiento bancario de los partidos políticos respecto del total de su pasivo corriente y no corriente

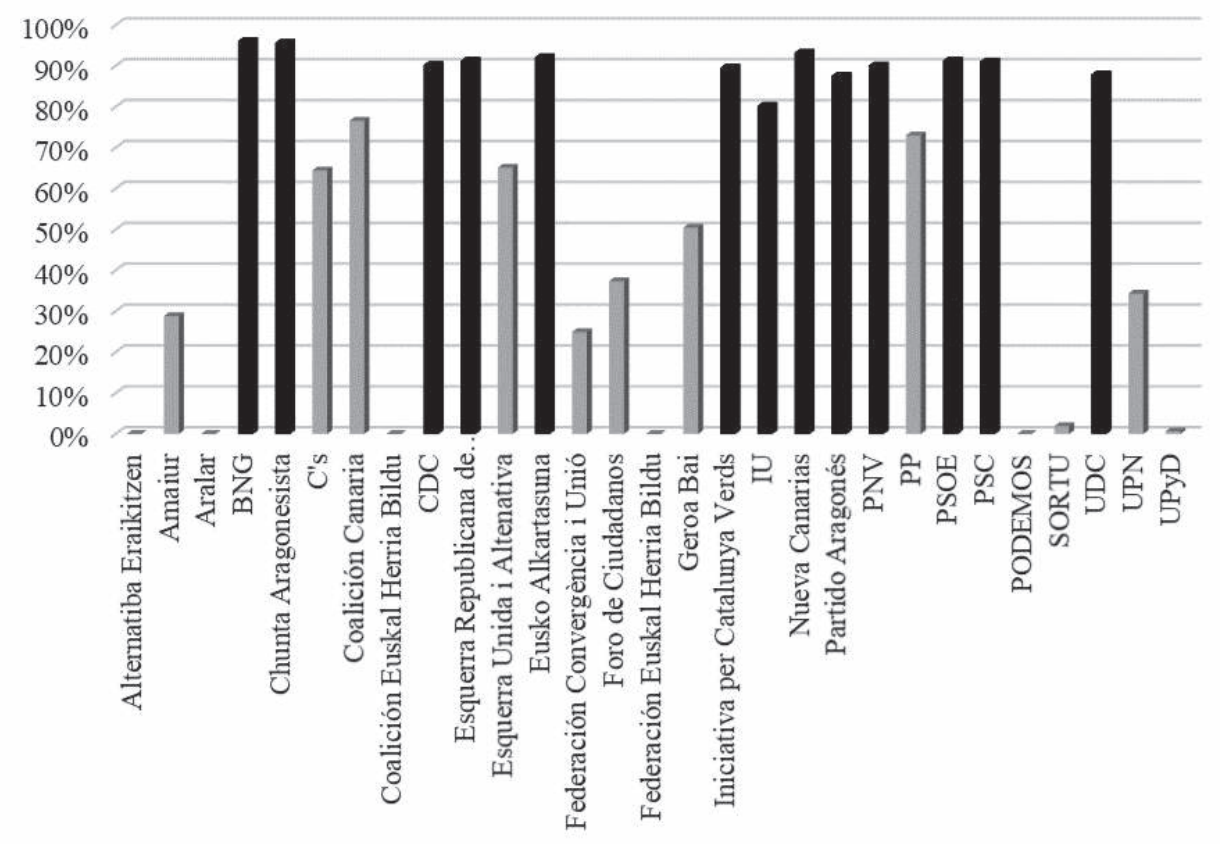

Fuente: Elaboración propia a partir de los datos reflejados en el Informe del Tribunal de Cuentas de fiscalización de los estados contables de los partidos politicos y de las aportaciones percibidas por las fundaciones y asociaciones vinculadas orgánicamente, ejercicios 2014 y 2015.

Preocupante es, a este respecto, la ratio de endeudamiento que presentan algunos partidos políticos. Su valor óptimo se sitúa, con carácter general, entre el $40 \%$ y el $60 \%$ del montante total de los fondos propios ubicándose, en dicha franja, el 62,07 \% $(\mathrm{n}=29)$ de los partidos analizados. En una situación de gran vulnerabilidad con relación a las entidades crediticias se hallan, por el contrario, el BNG, la Federación de $\mathrm{CiU}^{17}$ y UDC. Así, el coeficiente de endeudamiento de este último partido ascendía, en 2015 , a $297 \%$, lo que conllevaba que, por cada 2,97 € de financiación ajena, solo contaba con $1 €$ de fondos propios. Su elevado nivel de endeudamiento, unido a otros factores - la ruptura de la alianza con CiU, la pérdida de militantes y los resultados de las elecciones al Parla-

17 La Federación CiU estaba integrada por los partidos políticos Convergència Democrática de Catalunya (CDC) y Unió Democràtica de Catalunya (UDC). Con fecha de 31 de julio de 2015, se elevaron a público los acuerdos para su disolución. 
mento de Cataluña de 27 de septiembre de 2015- precipitó su disolución en 2017 tras su declaración en concurso de acreedores.

Fig. 11. Ratio de endeudamiento bancario de los partidos políticos

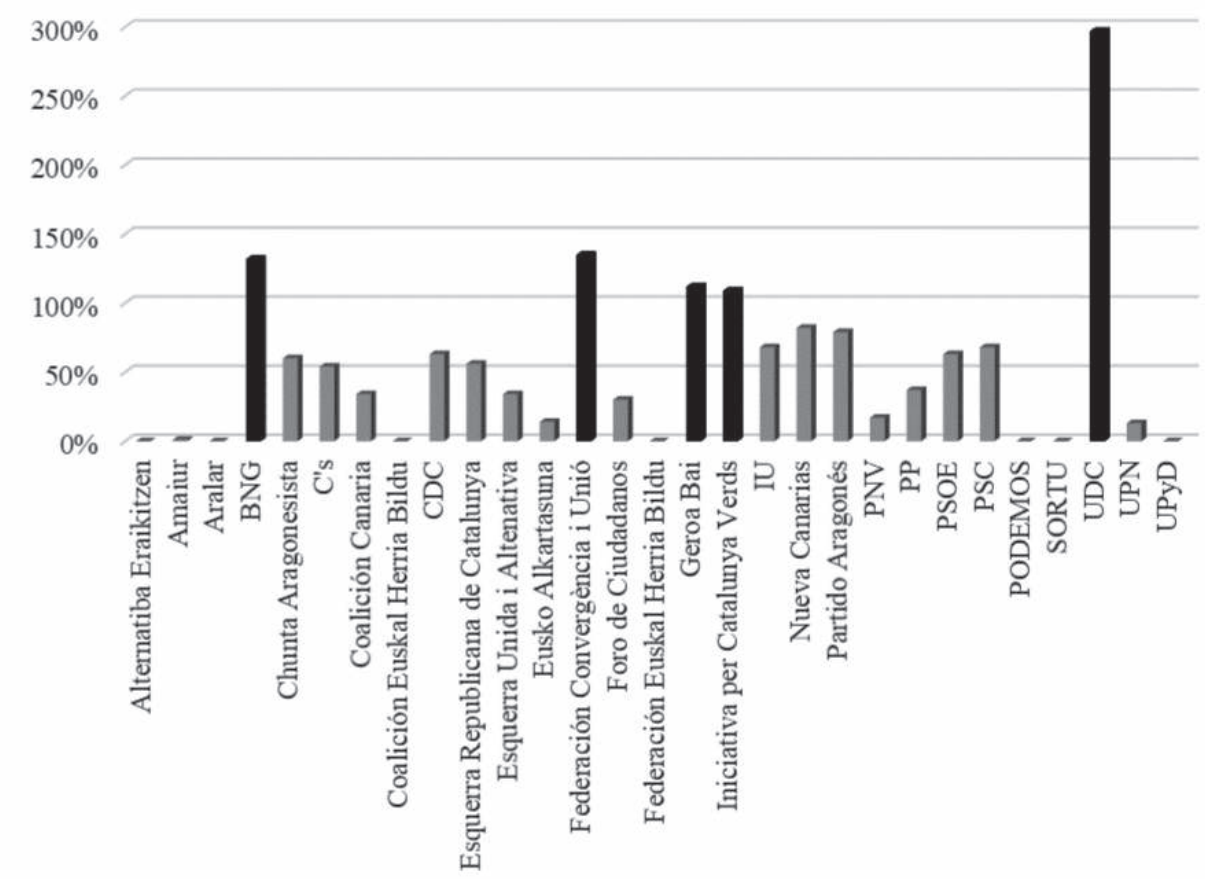

Fuente: Elaboración propia a partir de los datos reflejados en el Informe del Tribunal de Cuentas de fiscalización de los estados contables de los partidos políticos y de las aportaciones percibidas por las fundaciones y asociaciones vinculadas orgánicamente, ejercicios 2014 y 2015.

\section{La publicidad de la información sobre los créditos bancarios a los partidos políticos}

El control de la actividad económico-financiera de los partidos políticos corresponde, en exclusiva, al Tribunal de Cuentas. Esta actividad fiscalizadora comprende tanto la legalidad de sus recursos públicos y privados como la regularidad contable de las actividades económicofinancieras que realicen (arts. 16 LO 8/2007 y 1 Ley Orgánica 2/1982, de 2 de mayo, del Tribunal de Cuentas). A tal efecto, los partidos políticos deberán remitir al Tribunal de Cuentas, antes del 30 de junio del año siguiente al que se refieran, sus cuentas anuales consolidadas y debidamente formalizadas, en las que se detallarán y documentarán sus ingre- 
sos y gastos. Dichas cuentas anuales comprenderán el Balance, la Cuenta de Resultados y una Memoria explicativa de ambos (art. 14.3 LO 8/2007).

En lo que a nosotros aquí interesa, esta Memoria deberá ir acompañada, igualmente, de un anexo donde se especifiquen, pormenorizadamente, las condiciones contractuales estipuladas de los créditos o préstamos de cualquier clase que mantenga el partido con las entidades de crédito. En él se identificará a la entidad concedente, el importe otorgado, el tipo de interés y el plazo de amortización del crédito o préstamo y la deuda pendiente al cierre del ejercicio de que se trate, con indicación de cualquier contingencia relevante sobre el cumplimiento de las condiciones pactadas (art. 14.3 LO 8/2007).

Asimismo, los partidos políticos deberán publicar en su página web, en el plazo máximo de un mes desde la fecha de su remisión al Tribunal de Cuentas, el balance, la cuenta de resultados y, en particular, la cuantía de los créditos pendientes de amortización con especificación, en este último caso, de la entidad concedente, el importe otorgado, el tipo de interés y el plazo de amortización (art. 14.8 LO 8/2007). A este respecto, en el año 2015, solo 11 de las 29 formaciones políticas analizadas habían publicado, en su página web, sus cuentas anuales (Tribunal de Cuentas, 2018).

Estas medidas, que tienen por finalidad la búsqueda de una mayor transparencia en el ámbito de la financiación de los partidos políticos, no se predican, por el contrario, respecto de los acuerdos de renegociación de las condiciones de la deuda los cuales únicamente han de ser comunicados al Tribunal de Cuentas y al Banco de España (art. 4.4 LO 8/2007). En este caso, la difusión pública de esta información se realiza, únicamente, a través del correspondiente informe de fiscalización anual del Tribunal de Cuentas que suelen publicarse transcurridos una media de cuatro años a contar desde el concreto periodo temporal fiscalizado.

En este ámbito, desde el año 2014, Transparencia Internacional España ha realizado tres rondas de evaluación a efectos de valorar el nivel de transparencia de los partidos políticos. En atención a la última de ellas, concluida en 2017, el nivel medio de transparencia de las formaciones evaluadas 18 era de 27,7 puntos sobre 30 (TI España, 2017) 19.

18 Los once Partidos políticos evaluados por Transparencia Internacional España en 2017 fueron los siguientes: Partido Popular (PP), Partido Socialista Obrero Español (PSOE), Izquierda Unida (IU), Partido Nacionalista Vasco (PNV), Coalición Canaria (CC), Esquerra Republicana de Catalunya (ERC), Ciudadanos-Partido de la Ciudadanía (C's), Podemos (POD), Partido Socialista de Cataluña (PSC), Unión Progreso y Democracia (UPyD) y EQUO.

19 Disponible en: https://transparencia.org.es/evaluacion-del-nivel-de-transparenciade-los-partidos-politicos-2017/, [último acceso: 2020]. 


\section{Fig. 12. Nivel de transparencia de los partidos políticos}

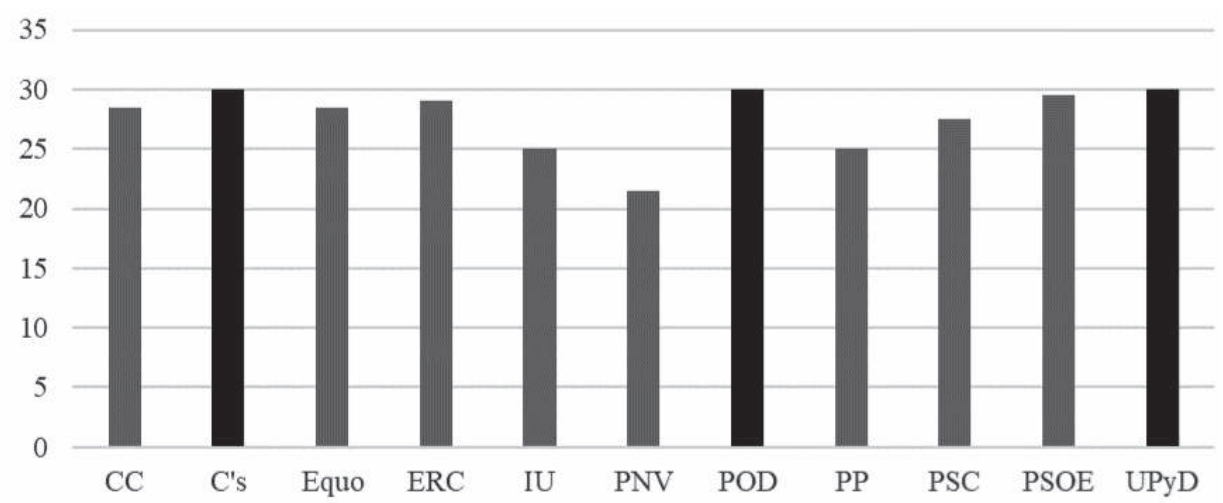

Fuente: Transparencia Internacional España

Por su parte, en el informe elaborado, en ese mismo año, por la Fundación Compromiso y Transparencia (FCyT), solo 13,04\% $(\mathrm{n}=3)$ de los 23 partidos analizados fueron clasificados como transparentes ${ }^{20}$, en tanto que un $30,43 \%$ se catalogaron como opacos ${ }^{21}$. El nivel medio de transparencia fue, en este caso, de 11,91 puntos sobre $29^{22}$.

\section{Fig. 13. Evolución del nivel de transparencia de los partidos} políticos

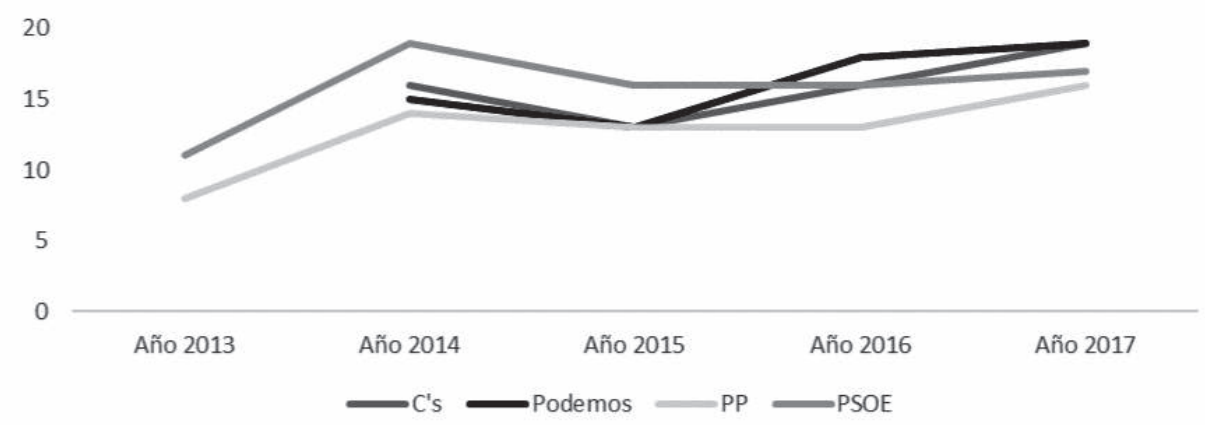

Fuente: Fundación Compromiso y Transparencia

20 Unión del Pueblo Navarro (20), Podemos (19) y Ciudadanos (19).

21 Esquerda Unida País Valencià (8), Partido Demócrata Europeo Catalán (7), Esquerda Unida (4), Anova (3), En Comú Podem (3), EH Bildu (2), Catalunya Sí (2).

22 Disponible en: https://www.compromisoytransparencia.com/categorias-informes/ partidos-politicos, [último acceso: 2020]. 
En cuanto a la publicación de información detallada sobre aspectos relativos a los créditos bancarios -la entidad financiera que los había concedido, el importe, el tipo de interés y el plazo de amortización-, en el estudio realizado por TI España solo Izquierda Unida no había procedido a facilitar tal información, en tanto que en el informe elaborado por FCyT se registraron un total de 11 formaciones (47,83\%) -Izquierda Unida, Equo, Coalició Compromís, En Marea, Esquerda Unida País Valencià, Partido Demócrata Europeo Catalán, Esquerda Unida, Anova, En Comú Podem, Eh Bildu, Catalunya Sí- que no publicitaban tales aspectos.

En todo caso, como acertadamente señala ALMAGRO CASTRO (2015), pese al indudable avance que estas previsiones suponen, este juicio positivo "debe relativizarse si se entiende que el verdadero problema no es tanto la identificación de las donaciones sino la opacidad de aquéllas que, conociéndose su existencia, escapan al control del Tribunal de Cuentas y al conocimiento directo de los electores (...)».

\section{Conclusiones}

Los datos expuestos no hacen más que corroborar la enorme dependencia que los partidos políticos españoles todavía presentan con respecto a las entidades de crédito, con los consiguientes riesgos que ello comporta en términos de injerencia en la conformación de la voluntad política. La ausencia de límite alguno en cuanto al endeudamiento bancario sigue representando el principal problema en el ámbito de su financiación.

En el año 2015 procedió a reformarse la LO 8/2007 a efectos de, entre otras cuestiones, prohibición a las entidades de crédito efectuar condonaciones totales o parciales de deuda a los partidos políticos (art. 4.4 LO 8/2007). El incumplimiento de dicha prohibición dará lugar a la comisión de una infracción grave (art. 17 Dos. a LO 8/2007) que lleva aparejada una sanción cuyo importe será entre el doble y el quíntuplo de la cantidad condonada (art. 17 bis Uno. a LO 8/2007).

No obstante, pese a la conceptuación de estas condonaciones como «donaciones encubiertas», ninguna previsión se contiene, a este respecto, en la regulación del delito de financiación ilegal de partidos políticos (art. 304 bis CP). Así, para el ordenamiento jurídico-penal, no existe problema alguno porque un banco condone, como hemos visto, una deuda crediticia vencida de hasta 10,23 millones de euros a un partido político, pero sí que una persona jurídica le done $1 €$. De todo ello parece inferirse que, para el legislador, es preferible la dependencia de los partidos políticos respecto de las entidades de crédito que con relación a otros grupos económicos y de poder. 
Al hilo de nuestra exposición, resulta evidente que el mundo económico sigue estando habilitado para orientar, frente a los designios de la voluntad popular, el devenir de las políticas públicas. Así, no se entiende que el legislador haya circunscrito el ámbito objetivo del tipo a las aportaciones y donaciones privadas que representan, únicamente, el 2,49\% del total de sus recursos. Tampoco se comprende que haya excluido de su ámbito subjetivo a las fundaciones y entidades vinculadas a los partidos políticos, lo que las convierte en una vía idónea para financiar, de forma paralela, a los partidos políticos. Aunque ciertamente, «pudiendo evitarlo, nadie propende a la autolimitación o a las autorestricciones, y los partidos políticos tampoco son en esto una excepción» (SANJUJO RIVO, 2018).

En suma, la expresa tipificación del delito de financiación ilegal no deja de ser una nueva manifestación de Derecho penal simbólico con la que, simplemente, se ha pretendido dar satisfacción a las demandas de la sociedad ante los diversos escándalos de corrupción política que se han registrado en nuestro país, pero no solventar, de raíz, el problema.

\section{Bibliografía}

Almagro Castro, D. (2015). A vueltas con la financiación de los partidos en España: La LO 8/2007 y las reformas de octubre de 2012 y marzo 2015. Estudios de Deusto: revista de la Universidad de Deusto, 63 (1), 171-203.

Bustos Rubio, M. (2016). El nuevo delito de financiación ilegal de partidos políticos. Revista Penal, 37, 61-79.

Coello de Portugal, J.M. (2012). La Ley Orgánica 5/2012, de 22 de octubre, una buena reforma en una buena dirección del régimen de financiación de los partidos políticos. Foro Nueva Época, 15 (2), 337-344.

Corcoy Bidasolo, M., Gallego Soler, J.I. (2017). «De los delitos de financiación ilegal de los partidos políticos». En M. Corcoy Bidasolo y S. Mir Puig (dirs.), Comentarios al Código Penal. Reforma LO 1/2015 y LO 2/2015 (pp. 1050-1052). Valencia: Tirant lo Blanch.

De la Mata BarRanco, N.J. (2016). La lucha contra la corrupción política. Revista Electrónica de Ciencia Penal y Criminología (RECPC), 20-28, 1-25.

Guardiola LAGO, $\mathrm{M}^{\mathrm{a}}$.J. (2018). Cuestiones generales sobre la responsabilidad penal y política de los partidos. (Seminario celebrado en la UAB el 20 de nov. 2015). En M. García Arán (dir.), Responsabilidad jurídica $y$ política de los partidos en España (pp. 27-44). Valencia: Tirant lo Blanch. 
holgado gonzález, M. (2003). La financiación de los partidos políticos en España, Valencia: Tirant lo Blanch.

Javato Martín, A.M ${ }^{\text {a }}$ (2017). El delito de financiación ilegal de los partidos políticos (arts. 304 bis y 304 ter CP). Aspectos dogmáticos, político-criminales y de derecho comparado. Revista Electrónica de Ciencia Penal y Criminología (RECPC), 19-26, 1-41.

- (2016). «Delito de financiación ilegal». En M. Gómez Tomillo (dir.), Comentarios Prácticos al Código Penal (pp. 717-729). Pamplona: Aranzadi.

LÉOn Alapont, J. (2019a). La responsabilidad penal de los partidos políticos, Valencia: Tirant lo Blanch.

- (2019B). La reforma de los delitos de financiación ilegal de partidos políticos: un debate desenfocado. Estudios Penales y Criminológicos, 39, 541-591.

- 2018. El delito de financiación ilegal de los partidos políticos dese la perspectiva de la responsabilidad penal de éstos como personas jurídicas. InDret: Revista para el Análisis del Derecho, 4, 1-37.

Macías EsPejo, B. (2018). Del delito de participación en estructuras u organizaciones con finalidad de financiación ilegal de partidos políticos (art. 304 ter del Código Penal). Dereito: revista xurídica da Universidade de Santiago de Compostela, 27 (1), 9-25.

- (2016). Sobre la incriminación de la financiación ilegal de partidos políticos en el artículo 304 bis del Código Penal. Cuadernos de Política Criminal, 119, 121-156.

Maroto Calatayud, M. (2015a). La financiación ilegal de los partidos políticos. Un análisis político-criminal, Madrid: Marcial Pons.

- (2015B). Financiación ilegal de partidos políticos. En G. Quintero Olivares (dir.), Comentario a la reforma penal de 2015 (pp. 755-769). Pamplona: Aranzadi.

Muñoz Cuesta, J. (2015). Delitos de financiación ilegal de partidos políticos. Revista Aranzadi Doctrinal, 5, 11-21.

Nieto Martín, A. (2006). Financiación ilegal de partidos políticos (arts. 10-13). En L.A. Arroyo Zapatero y A. Nieto Martín (coords.), Fraude y corrupción en el Derecho penal económico europeo. Eurodelitos de corrupción y fraude (pp. 117-138). Cuenca: Universidad de Castilla-La Mancha.

NúÑEz CASTAÑo, E. (2017a). Sobre la legitimidad de la tipificación penal de financiación ilegal de partidos políticos en el marco de la regeneración democrática y la lucha contra la corrupción. En $\mathrm{M}^{\mathrm{a}}$. C. Gómez Rivero y A. Barrero Ortega (dirs.), Regeneración democrática y estrategias penales en la lucha contra la corrupción (pp. 731-789). Valencia: Tirant lo Blanch. 
NúÑEz CASTAÑo, E. (2017b). La cuestionable regulación penal de los delitos de financiación ilegal de partidos políticos. Revista Penal, 39, 125-153.

- (2015). El delito de financiación ilegal de partidos políticos y la Unión Europea: un caso de corrupción al margen de la normativa europea. En $\mathrm{M}^{\mathrm{a}}$. I. González Cano (dir.), Cooperación judicial penal en la Unión Europea: reflexiones sobre algunos aspectos de la investigación y el enjuiciamiento en el espacio europeo de justicia penal (pp. 61-104). Valencia: Tirant lo Blanch.

Odriozola GuRRutXaga, M. (2018). La regulación penal de la financiación ilegal de partidos políticos. Cuadernos de Política Criminal, 126, 89-136.

Olaizola Nogales, I. (2015a). Las reformas legales relacionadas con la financiación de los partidos políticos en España. En A. Jareño Leal y A. Doval País (dirs.), Corrupción pública, prueba y delito (pp. 253-284). Pamplona: Thomson Reuters-Aranzadi.

- (2015B). El delito de financiación ilegal de partidos políticos en la reforma del CP. Diario La Ley, 8516, 1-6.

- (2015c). Medidas de regeneración democrática. La nueva regulación de la financiación de los partidos políticos en España. Estudios de Deusto: revista de la Universidad de Deusto, 63 (1), 327-358.

- (2014). La financiación ilegal de los partidos políticos: un foco de corrupción, Valencia: Tirant lo Blanch.

OrdoÑEz PÉREZ, D. (2012). La financiación de los partidos políticos en España: corrupción y deslegitimación. Estudios. Revista de Pensamiento Libertario, 2, 19-26.

Pérez Rivas, N. (2019). El delito de financiación ilegal de los partidos políticos. En R. L. Blanco Valdés y F. Vázquez-Portomeñe Seijas (dirs.), Nuevos instrumentos jurídicos en la lucha contra la corrupción pública: propuestas desde el Derecho Penal y el Derecho Constitucional (pp. 105-126). Valencia: Tirant lo Blanch.

Preciado Domènech, C.H. (2015). La corrupción pública en la reforma del Código Penal de 2015, Pamplona: Civitas.

Puente Aba, L.M ${ }^{a}$. (2017). El delito de financiación ilegal de partidos politicos. Valencia: Tirant lo Blanch.

- (2015). Financiación ilegal de partidos políticos (art. 304 bis CP). En J. L. González Cussac (dir.), Comentarios a la reforma del Código penal de 2015 (pp. 949-960). Valencia: Tirant lo Blanch.

Rebollo Vargas, R. (2018). La polémica en el delito de financiación de partidos políticos: las puertas continúan abiertas. Estudios Penales y Criminológicos, 38 (núm. extr.), 59-100. 
Ruiz-Rico Ruiz, G. (2014). La lucha contra la corrupción desde el Estado constitucional de derecho: la legislación sobre financiación de partidos políticos en España. Cuadernos Manuel Giménez Abad, 7, 223-241.

SÁINZ-CANTERo CAPARRós, J.E. (2015). Los delitos de financiación ilegal de los partidos políticos. En L. Morillas Cueva (dir.), Estudios sobre el Código penal reformado. Leyes Orgánicas 1/2015 y 2/2015 (pp. 659689). Madrid: Dykinson.

SÁNCHEz MuÑoz, O. (2013). La financiación de los partidos políticos en España: ideas para un debate. Revista Española de Derecho Constitucional, 99, 161-200.

SANJURJo Rivo, V. (2018). Financiación de partidos políticos y transparencia: crónica de una resistencia. Estudios Penales y Criminológicos, 38 (núm. extr.), 443-477.

Sierra López, Ma .V. (2017). El delito de financiación ilegal de partidos políticos: ¿mayor eficacia en la lucha contra la corrupción?. En $\mathbf{M}^{\mathrm{a}}$. C. Gómez Rivero y A. Barrero Ortega (dirs.), Regeneración democrática y estrategias penales en la lucha contra la corrupción (pp. 791-825). Valencia: Tirant lo Blanch.

\section{Informes}

\section{Grupo de Estados contra la Corrupción (GRECO)}

Tercera Ronda de Evaluación. «Informe de Evaluación sobre Transparencia en la Financiación de Partidos Políticos en España», (28 de mayo de 2009), disponible en https://rm.coe.int/16806c9d70, [último acceso: 2020].

Third Evaluation Round. Compliance Report on Spain. "Incriminations (ETS 173 and 191, GPC 2). Transparency of Party Funding», (12 de abril de 2011), disponible en https://rm.coe.int/16806c9daf, [último acceso: 2020].

Third Evaluation Round. Second Compliance Report on Spain. "Incriminations (ETS 173 and 191, GPC 2). Transparency of Party Funding», (11 de julio de 2013), disponible en https://rm.coe.int/16806c9db2 [último acceso: 2020].

Third Evaluation Round. Addendum to the Second Compliance Report on Spain. Incriminations (ETS 173 and 191, GPC 2). Transparency of Party Funding, (3 de marzo de 2015). Disponible en: https://rm.coe. int/16806c9db6 [último acceso: 2020].

Third Evaluation Round. Second Addendum to the Second Compliance Report on Spain. Incriminations (ETS 173 and 191, GPC 2). Transparency 
of Party Funding, (9 de febrero de 2016). Disponible en: https://rm.coe. int/16806cac21 [último acceso: 2020].

\section{Tribunal de Cuentas}

Informe de fiscalización de los estados contables de los partidos políticos y de las donaciones percibidas por las fundaciones vinculadas orgánicamente, ejercicio 2007. BOE, 5 de marzo de 2013, núm. 55.

Informe de fiscalización de los estados contables de los partidos politi$\cos y$ de las donaciones percibidas por las fundaciones vinculadas orgánicamente, ejercicio 2008. BOE, 11 de febrero de 2014, núm. 36.

Informe de fiscalización de los estados contables de los partidos políticos y de las donaciones percibidas por las fundaciones vinculadas orgánicamente, ejercicios 2009, 2010 y 2011. BOE, 12 de mayo de 2014, núm. 115.

Informe de fiscalización de los estados contables de los partidos políticos y de las aportaciones percibidas por las fundaciones y asociaciones vinculadas orgánicamente, ejercicio 2013. BOE, 7 de abril de 2017, núm. 83.

Informe de fiscalización de los estados contables de los partidos politicos y de las aportaciones percibidas por las fundaciones y asociaciones vinculadas orgánicamente, ejercicios 2014 y 2015. BOE, 26 de abril de 2018, núm. 101. 